\title{
The Fatty Acid Synthase of the Basidiomycete Omphalotus olearius Is a Single Polypeptide
}

\author{
Luis Antelo ${ }^{\mathrm{a}, *}$, Angela Schlipp ${ }^{\mathrm{a}}$, Carolin Hof $^{\mathrm{a}}$, Katrin Eisfeld ${ }^{\mathrm{a}}$, Holger Berg ${ }^{\mathrm{b}}$, \\ Till Hornbogen ${ }^{\mathrm{b}}$, Rainer Zocher ${ }^{\mathrm{b}, \dagger}$, and Heidrun Anke ${ }^{\mathrm{a}}$ \\ a IBWF, Institut für Biotechnologie und Wirkstoff-Forschung e. V., \\ Erwin-Schrödinger-Str. 56, D-67663 Kaiserslautern, Germany. E-mail: antelo@ibwf.de \\ b Technische Universität Berlin, Fakultät II - Institut für Chemie, AG Biochemie und \\ Molekulare Biologie, Franklinstr. 29, D-10587 Berlin, Germany \\ * Author for correspondence and reprint requests \\ Z. Naturforsch. 64c, 244-250 (2009); received November 6/December 12, 2008
}

Fatty acids are essential components of almost all biological membranes. Additionally, they are important in energy storage, as second messengers during signal transduction, and in post-translational protein modification. De novo synthesis of fatty acids is essential for almost all organisms, and entails the iterative elongation of the growing fatty acid chain through a set of reactions conserved in all kingdoms. During our work on the biosynthesis of secondary metabolites, a 450-kDa protein was detected by SDS-PAGE of enriched fractions from mycelial lysates from the basidiomycete Omphalotus olearius. Protein sequencing of this protein band revealed the presence of peptides with homology to both $\alpha$ and $\beta$ subunits of the ascomycete fatty acid synthase (FAS) family. The FAS encoding gene of $O$. olearius was sequenced. The positions of its predicted 21 introns were verified. The gene encodes a 3931 amino acids single protein, with an equivalent of the ascomycetous $\beta$ subunit at the $\mathrm{N}$-terminus and the $\alpha$ subunit at the C-terminus. This is the first report on an FAS protein from a homobasidiomycete and also the first fungal FAS which is comprised of a single polypeptide.

Key words: Omphalotus olearius, Fatty Acid Synthase, Basidiomycete

\section{Introduction}

Fatty acids are essential components of life. They have very diverse biological functions in contrast to their structural simplicity. Fatty acids are constituents of neutral or polar lipids [except for archaea (Schweizer and Hofmann, 2004)] playing a role in the integrity and dynamics of biological membranes. They are also present as side chains in some coenzymes, secondary metabolites, as well as in post-translational modifications of proteins. Furthermore, they represent an important form of energy storage and, as parts of second-messenger molecules, are involved in the modulation of gene expression (Schweizer and Hofmann, 2004; Maier et al., 2006).

Synthesis of fatty acids is present in almost all organisms. Malassezia globosa is one exception and its apparent lack of fatty acid synthase genes is compensated by the abundance of genes encoding hydrolases that might be involved in the re-

$\uparrow$ Rainer Zocher deceased on March 26, 2008. lease of fatty acids from lipids in its environment (Xu et al., 2007).

De novo synthesis of fatty acids involves a set of conserved reactions for the cyclic elongation of precursors and requires a multienzyme complex. First, there is the acyl transfer from acetyl and malonyl coenzyme A to the prosthetic phosphopantetheine group of the acyl carrier protein (ACP) by an acetyl transferase (AT) and malonyl transferase (MT). The enzyme-bound substrates are then condensed by the ketoacyl synthase (KS) by decarboxylation of the malonyl to acetoacetylACP, which is further reduced by a ketoacyl reductase (KR), dehydrated by a dehydratase (DH) and reduced by an enoyl reductase (ER) to form butyryl-ACP. These reactions are repeated six times. The mammalian fatty acid synthases (FASs) release the newly formed fatty acid by a thioesterase (TE) whereas in fungi it is transferred back from the ACP to coenzyme A by an MT (Jenni et $a l ., 2006)$. The fatty acids are further elongated by elongases (Rawlings, 1998). 
Although the synthesis of fatty acids is similar in all organisms, three different molecular architectures of FASs have developed during evolution. The type II FASs, present in most bacteria and plants, consist of independent proteins for the different enzymatic activities encoded by discrete genes. In contrast, type I FASs are highly integrated multienzymes, which contain the various catalytic domains in one or two polypeptide chains. The type I FASs can be subdivided in two groups according to the domain organization and subunit stoichiometry (Schweizer and Hofmann, 2004). Animal FASs (type Ib) are $\alpha_{2}$ dimers with the domain sequence KS-AT-DH-ER-KR-ACP$\mathrm{TE}$, and have an asymmetric $\mathrm{X}$-shape. In ascomycetes, FASs are barrelshaped $\alpha_{6} \beta_{6}$ oligomers with the domain sequence ACP-KR-KS-PPT for the $\alpha$ subunit (PPT for phosphopantetheinyl transferase) and AT-ER-DH-MT for the $\beta$ subunit (Fig. 1) (Lynen, 1980; Jenni et al., 2006).

There are other examples of multienzyme complexes grouped in single polypeptides in fungi. Type I polyketide synthases (PKSs) are very large multifunctional proteins with individual functional domains, while the type II PKSs, present only in bacteria, are built up by individual proteins (Cox, 2007). Fungal nonribosomal peptide synthetases (NRPSs) usually consist of a single polypeptide containing all modules necessary for the synthesis of the corresponding secondary metabolite, whereas their bacterial counterparts, in most cases, are distributed on more than one peptide chain (Doekel and Marahiel, 2001).

During our work on proteins involved in the biosynthesis of secondary metabolites a $450-\mathrm{kDa}$ protein was detected. To our surprise, this large protein was found to be a fatty acid synthase and therefore, it is involved in primary metabolism. Since such large proteins are not common among fatty acid synthases from fungi, an attempt was made to further characterize this enzyme. Here we describe the partial purification, microsequencing and identification of the FAS protein of the homobasidiomycete Omphalotus olearius, as well as the identification of the FAS gene and the analysis of its cDNA.

\section{Material and Methods}

\section{Organisms, media, and cultivation conditions}

The mycelial culture of $O$. olearius TA90170 was obtained from a spore print of a fruiting body attached onto the lid of a Petri dish. Basidiospores were collected on YMG solid medium (4 g/l yeast extract; $10 \mathrm{~g} / \mathrm{l}$ malt extract; $4 \mathrm{~g} / \mathrm{l}$ glucose; $\mathrm{pH}$ 5.5) containing penicillin $(100 \mathrm{mg} / \mathrm{l})$, streptomycin $(200 \mathrm{mg} / \mathrm{l})$ and $1.5 \%$ of agar. The culture resulting from the germinated spores is deposited at the IBWF, Kaiserslautern, Germany. The strain was cultivated and maintained in YMG medium. Fermentations up to 21 were carried out in 5-1 Erlenmeyer flasks with agitation $(120 \mathrm{rpm})$ at $28^{\circ} \mathrm{C}$. Larger fermentations were carried out in a Biostat A-20 fermenter (Braun, Melsungen, Germany) containing 201 of YMG medium at $28^{\circ} \mathrm{C}$ with aeration $(3 \mathrm{l} / \mathrm{min})$ and agitation $(120 \mathrm{rpm})$.

The Escherichia coli strain DH5a (Gibco BRL, Rockville, MD, USA) was used for cloning and plasmid propagation.

\section{Enzyme purification}

All operations were carried out at $4{ }^{\circ} \mathrm{C}$. Lyophilized mycelium of $O$. olearius $(10 \mathrm{~g})$ was homog-

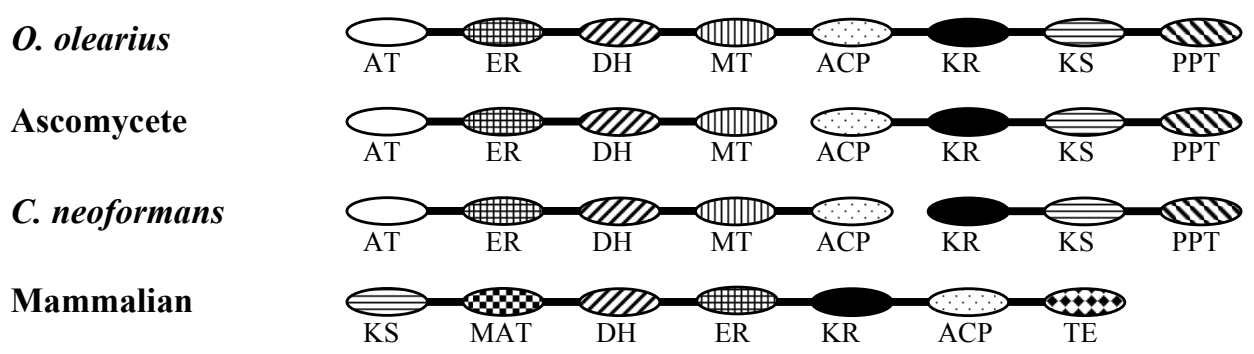

Fig. 1. Diagrammatic comparison of domain organization of O. olearius, ascomycete, C. neoformans, and mammalian type I FAS. KS, $\beta$-ketoacyl synthase; AT, acetyl-CoA-ACP transacetylase; MT, malonyl-CoA-ACP-transacylase; $\mathrm{DH}$, dehydratase; ER, $\beta$-enoyl reductase; $\mathrm{KR}, \beta$-ketoacyl reductase; ACP, acyl carrier protein; PPT, phosphopantetheinyl transferase; MAT, malonyl-CoA-acetyl-CoA-ACP transacylase; TE, thioesterase. 
enized in a mortar with liquid nitrogen and extracted with buffer A [200 mM tris(hydroxymethyl) aminomethane- $\mathrm{HCl}$ (Tris- $\mathrm{HCl}$ ), $\mathrm{pH} 8.0,625 \mathrm{~mm}$ $\mathrm{NaCl}, 10 \%$ glycerol, $1 \mathrm{~mm}$ EDTA, $20 \mathrm{~mm}$ dithiothreitol, $5 \mathrm{~mm}$ benzamidine, $5 \mathrm{~mm}$ phenylmethylsulfonylfluoride] by gentle stirring for $1 \mathrm{~h}$. The extract was centrifuged for $20 \mathrm{~min}$ at $15,000 \mathrm{rpm}$ using an SS-34 rotor in a Beckmann JM-21 centrifuge. A solution of polyethylene imine $(8.7 \%$, $\mathrm{pH} 7$ ) was added to the supernatant to give a final content of $0.3 \%$; the mixture was kept on ice for $10 \mathrm{~min}$. The extract was centrifuged for $10 \mathrm{~min}$ at $15,000 \mathrm{rpm}$. The supernatant was brought to a final ammonium sulfate saturation of $70 \%$ by adding saturated ammonium sulfate solution ( $\mathrm{pH} \mathrm{8.0)}$ ), and was centrifuged for $10 \mathrm{~min}$ at $15,000 \mathrm{rpm}$. The resulting pellet was resuspended in buffer B (15\% w/v glycerol, $100 \mathrm{~mm}$ Tris- $\mathrm{HCl}$, pH 8.0, $1 \mathrm{~mm}$ EDTA, $50 \mathrm{~mm} \mathrm{NaCl}, 4 \mathrm{~mm}$ DTE, $1 \mathrm{~mm}$ benzamidine, $1 \mathrm{~mm}$ PMSF) and applied to a Ultrogel AcA34 (Pall, East Hills, NY, USA) size exclusion column $(50 \mathrm{~cm} \times 3.0 \mathrm{~cm})$. The proteins were eluted with buffer $\mathrm{B}$ and $5-\mathrm{ml}$ fractions were collected. $2 \mathrm{ml}$ of the fractions were precipitated with sodium deoxycholate-trichloroacetic acid according to Bensadoun and Weinstein (1976) and separated by a minifuge (Eppendorf, Hamburg, Germany). The resulting pellets were resuspended in sample buffer according to Piccioni et al. (1982) and applied to SDS-PAGE.

\section{Protein determination}

Protein concentrations were determined by using a modified Bradford procedure with bovine serum albumin as a standard (Bradford, 1976).

\section{SDS-polyacrylamide gel electrophoresis}

SDS-polyacrylamide gel electrophoresis (SDSPAGE) was performed according to the method of Laemmli (1970). Gels contained 4\% acrylamide. The relative molecular mass of the protein was determined from its mobility related to those of the standard proteins cyclosporin synthase $(1,700 \mathrm{kDa})$ and enniatin synthase (350 kDa) (Sigma, high molecular weight markers). Cyclosporin synthase was isolated from Tolipocladium inflatum mycelium and enniatin synthase from Fusarium scirpi mycelium as previously described (Lawen and Zocher, 1990; Zocher et al., 1982). Gels were stained with Coomassie Brilliant Blue.

\section{In-gel tryptic digestion}

A stained protein band corresponding to a molecular mass of approximately $450 \mathrm{kDa}$ was excised from the gel, cut into small pieces and destained with methanol/acetic acid/water (40:10:50). The gel pieces were incubated in acetonitrile for $10 \mathrm{~min}$, the solvent was removed, and the gel pieces were dried in a vacuum centrifuge for $3 \mathrm{~min}$. Reduction was performed by addition of $10 \mathrm{~mm}$ DTT in $100 \mathrm{~mm} \mathrm{NH}_{4} \mathrm{HCO}_{3}$ for $30 \mathrm{~min}$ at room temperature. The solution was removed and $100 \mathrm{~mm}$ iodoacetamide in $100 \mathrm{~mm} \mathrm{NH}_{4} \mathrm{HCO}_{3}$ was added during $30 \mathrm{~min}$ at room temperature for alkylation of the thiol groups. The gel pieces were dehydrated with acetonitrile and rehydrated with $100 \mathrm{~mm} \mathrm{NH}_{4} \mathrm{HCO}_{3}$ twice. After a last dehydration step with acetonitrile, $30 \mu \mathrm{l}$ of $20 \mathrm{ng} / \mu \mathrm{l}$ trypsin (Sigma) in $50 \mathrm{~mm} \mathrm{NH}_{4} \mathrm{HCO}_{3}$ were added to the gel pieces, and incubation was carried out overnight at $37^{\circ} \mathrm{C}$. After enzymatic digestion, $30 \mu \mathrm{l}$ of $50 \mathrm{~mm} \mathrm{NH}_{4} \mathrm{HCO}_{3}$ were added, the supernatant was collected, and the gel pieces were extracted three times with acetonitrile/formic acid/water (50:5:45). The collected samples were pooled and dried in a vacuum centrifuge. The peptides were dissolved in $0.1 \%$ formic acid and desalting was done using $\mu$ C18-Ziptips (Millipore, Eschborn, Germany) following the manufacturer's instructions.

\section{Protein sequencing}

The desalted sample was loaded into a nanoelectrospray capillary (Waters Micromass, Manchester, UK). Measurements were performed in an electrospray (ESI) Q-TOF tandem mass spectrometer (Q-Tof 2, Waters Micromass). Peptides were fragmented in the collision chamber, using energies of $20-60 \mathrm{eV}$ and argon as the collision gas. Peptide fragments were detected using a time of flight (ToF) analyzer. Data acquisition and processing were conducted using the MassLynx software package (Waters Micromass).

\section{DNA and RNA isolation}

For genomic DNA isolation, lyophilized mycelium of $O$. olearius was ground to a fine powder. Extraction buffer ( $1 \mathrm{~m}$ Tris- $\mathrm{HCl}, \mathrm{pH} 8.0,0.1 \mathrm{~mm}$ EDTA, $1 \%$ SDS, $200 \mu \mathrm{g} / \mathrm{ml}$ proteinase $\mathrm{K}, 100 \mu \mathrm{g} /$ $\mathrm{ml}$ DNase-free RNase) was added and the mixture incubated for $50 \mathrm{~min}$ at $56^{\circ} \mathrm{C}$. The mixture 
was extracted once with phenol and three times with phenol/chloroform/isoamyl alcohol (25:24:1 $\mathrm{v} / \mathrm{v} / \mathrm{v}$ ) followed by a final extraction with chloroform/isoamyl alcohol $(24: 1 \mathrm{v} / \mathrm{v})$. To remove proteins, $0.1 \mathrm{vol}$ of $5 \mathrm{M}$ potassium acetate was added to the supernatant, the mixture was incubated for $1 \mathrm{~h}$ on ice and centrifuged. DNA was precipitated with 2 vol of ethanol and washed with $70 \%$ ethanol.

RNA was isolated by grinding lyophilized mycelium under liquid nitrogen. The fine powder was extracted with the Total RNA Isolation System (Promega, Madison, WI, USA) following the manufacturer's instructions. DNase treatment was performed by dissolving the RNA pellets in $200 \mu$ l buffer ( $0.1 \mathrm{M}$ sodium acetate, $5 \mathrm{~mm} \mathrm{MgSO}_{4}$, $\mathrm{pH}$ 5.0) containing 2 units of DNase and incubating for $20 \mathrm{~min}$ at room temperature, followed by a final phenol/chloroform extraction. RNA was precipitated with 2 vol ethanol and dissolved in $500 \mu \mathrm{l}$ of RNase-free water. mRNA was isolated from total RNA using the PolyATract mRNA Isolation System (Promega).

\section{Sequence analysis of FAS1}

A genomic fosmid bank of $O$. olearius was constructed using the EpiFOS ${ }^{\mathrm{TM}}$ Fosmid Library Production Kit (Epicentre Biotechnologies, Madison, WI, USA) following the manufacturer's instructions. A total of 1800 fosmid clones was examined by sequencing the 5 ' termini of the inserts. One clone exhibited homology to fungal fatty acid synthase genes. This gene fragment was used as a DIG-labelled probe (Roche, Basel, Switzerland) for screening of the fosmid bank. Three fosmids containing the FAS fragment were identified. The complete FAS gene was analyzed by sequencing the subclones of the fosmid inserts which hybridized with the probe.

To identify the introns contained in the FAS1, cDNA was generated from $O$. olearius mRNA using the OneStep RT-PCR Kit (Quiagen, Hilden, Germany). Gene-specific primers which covered the genomic sequence of the FAS1 were used for amplification of the cDNA fragments which were subsequently compared with the genomic sequence using Seqman (DNASTAR, Madison, WI, USA).

\section{Results and Discussion}

\section{Protein purification and sequencing}

During our search for proteins involved in the secondary metabolism of $O$. olearius, we enriched a large protein that later was identified as a fatty acid synthase (FAS). The FAS of $O$. olearius was partially purified from the mycelium after ammonium sulfate precipitation and size exclusion chromatography. A protein band, with an apparent molecular weight of $450 \mathrm{kDa}$, was visualized after SDS-PAGE (Fig. 2). This protein band was excised from the gel and protein microsequencing was performed. A total of 23 peptides could be successfully sequenced (Table I), most of them with homology to either the $\beta$ or the $\alpha$ subunits of known FAS from ascomycetes. Since electrophoresis was carried out under denaturing conditions, all peptides should belong to the same polypeptide chain. This finding correlates well with the putative FAS of the basidiomycetes Ustilago maydis and Coprinus cinereus, in which the $\alpha$ and $\beta$ subunits are predicted to be condensed in a single polypeptide. These putative proteins had been derived from genome sequencing projects,

Table I. List of peptides sequenced from the FAS of $O$. olearius. Proper leucine or isoleucine have been corrected by comparison with the sequence of the gene.

\begin{tabular}{ll}
\hline Sequenced peptides from O. olearius & Equivalent position in ascomycetous FAS \\
\hline VVVGYEGDVPSSVTIYGAAR; YIPNLIATPFEVSR; & $\beta$ subunit \\
EYASIIYDQTSSPR; VPDGVGVSLNSLYINPR; & \\
SIFPESIDGDLLK; LLTDLEGEELWK; EFDDTVFNLPK; & \\
ALIQNLLER; SYAGDASSVPVVDYLAGAR; & \\
PNALPLPVGISR; SIFPESIDGDLLK; & \\
SEANIVSVVNSPAGK; HGNPVLAYLQR & $\alpha$ subunit \\
\hline KLPGGFNSSAVK; ALYEGVVR; LPDLADITTR; & \\
LIQTVDVLPR; FNFPTLESSQSLSDLSTLR; LIEPELFR; & \\
YGLPEDILAQTDR; TALELGAPIR; TPGNAVPIIAQK; & \\
YLFGALDPAYYEAYK &
\end{tabular}


and no protein evidence has been presented so far. Thus, this is the first report, at the protein level, on a single polypeptide for the FAS in basidiomycetes.

\section{Molecular characterization of the FAS gene of $O$. olearius}

The sequence of the FAS gene of $O$. olearius (FAS1) (accession EU707901) was determined by overlapping and assembling the sequences of fosmide subclones, and it was found to have a length of $12962 \mathrm{bp}$. The entire cDNA sequence was analyzed by overlapping reverse transcribed PCR using RNA in order to determine the position and length of introns, as well as confirming the presence of a single mRNA. The comparison of cDNA and genomic sequences revealed the existence of 21 introns ranging in size from 50 to 67 $\mathrm{bp}$, which are distributed over the whole length of the gene (Fig. 3). The 5' and 3' boundaries in most cases match the consensus sequences for fungal introns (Balance, 1986; Kupfer et al., 2004). A high number of introns had previously been found in other genes of O. olearius (Welzel et al.,2005) and in basidiomycetous genes in general (Larrondo et al., 2004; Martinez et al., 2004). Comparison of the relative position of the introns of FAS1 and the putative FAS gene of $C$. cinereus shows a high degree of conservation. The $O$. olearius gene contains three additional introns. Conserved intron locations among members of gene families are not unusual and, for example, have also been shown

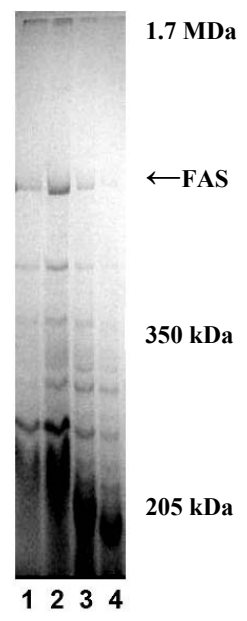

Fig. 2. SDS-PAGE analysis of four fractions from size exclusion chromatography (lanes $1-4)$. Molecular weight markers are indicated at the right-hand side. The putative FAS of $450 \mathrm{kDa}$ size is indicated with an arrow. The $450-\mathrm{kDa}$ protein band was excised from the gel and subjected to protein sequencing. for laccase genes and P450 multigene families (Hoegger et al., 2004; Doddapaneni et al., 2005).

The predicted protein encoded by the FAS 1 gene is a very large protein comprising 3931 amino acids with a mass of approximately $431 \mathrm{kDa}$, which is in agreement with the detected $450-\mathrm{kDa}$ protein band. It contains all peptides sequenced from the purified protein band (Table I), confirming that the FAS comprises a single polypeptide. The peptides sequenced represent $7.5 \%$ of the total protein sequence. The FAS1 possesses the highest similarity to the hypothetical FAS from C. cinereus (accession XP_001836417) with 75\% amino acid identity, indicating that FASs are highly conserved proteins. This has also been demonstrated for the FASs of ascomycetes. Among the FAS peptide sequences from Penicillium patulum, Candida albicans, Saccharomyces cerevisiae, Yarrowia lipolytica, and Aspergillus nidulans FasA proteins share $60 \%$ identity and FasB proteins exhibit 70\% identity (Brown et al., 1996).

During fatty acid synthesis, substrates are tethered to the prosthetic phosphopantetheine group of the ACP. Elongation of the growing fatty acid chain operates by directional shuttling of the intermediates to active centres of the KS domain (Leibundgut et al., 2007). The conserved motifs of this interaction could be identified in the $O$. olearius FAS as aa S2251, carrying the phosphopantetheine group, and aa C3347, H3584, H3620 and K3625, mediating the function of the KS domain (Leibundgut et al., 2007; Rawlings, 1998).

The domain organization of the FAS1 protein (Fig. 1) is identical to those of the putative FAS protein of the basidiomycetes $C$. cinereus and $U$. maydis, indicating that FASs from basidiomycetes generally differ from those of ascomycetes. Their domain organization (AT-ER-DH-MT-ACP-KR-

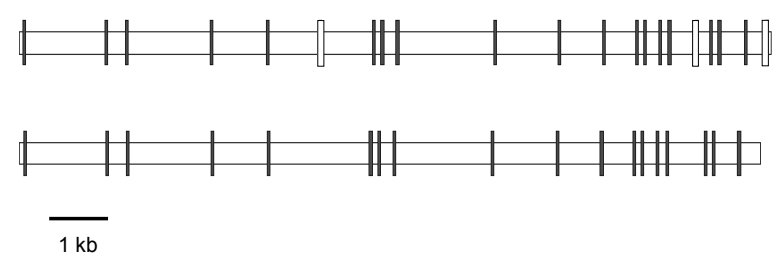

Fig. 3. Diagrammatic representation of intron distribution in the fatty acid synthases of $O$. olearius (top) and $C$. cinereus (bottom). Intron positions of both FAS genes are conserved, with the $O$. olearius gene containing three additional introns (empty bars). 
KS-PPT), however, is similar to those of the latter (Schweizer and Hofmann, 2004) provided that the $\beta$ subunit (AT-ER-DH-MT) is placed at the N-terminus and the $\alpha$ subunit (ACP-KR-KSPPT) is placed at the C-terminus of the FAS of the ascomycete type. Actually, it has been shown through the elucidation of the crystal structure of the FAS of Thermomyces lanuginosus (Jenni et al., 2007) that the $\mathrm{N}$-terminus of the $\alpha$ chain and the C-terminus of the $\beta$ chain are very close in space (8 ̊ apart).

Interestingly, the FAS of the basidiomycete Cryptococcus neoformans is composed of two subunits (Chayakulkeeree et al., 2007). But in this case the domain distribution differs from that of

Balance D. J. (1986), Sequences important for gene expression in filamentous fungi. Yeast 2, 229-236.

Bensadoun A. and Weinstein D. (1976), Assay of proteins in the presence of interfering materials. Anal. Biochem. 70, 241-250.

Bradford M. M. (1976), A rapid and sensitive method for the quantitation of microgram quantities of protein utilizing the principle of protein-dye binding. Anal. Biochem. 72, 248-254.

Brown D. W., Adams T. H., and Keller N. P. (1996), Aspergillus has distinct fatty acid synthases for primary and secondary metabolism. Proc. Natl. Acad. Sci. USA 93, $14873-14877$.

Chayakulkeeree M., Rude T. H., Toffaletti D. L., and Perfect J. R. (2007), Fatty acid synthesis is essential for survival of Cryptococcus neoformans and a potential fungicidal target. Antimicrob. Agents Chemother. 51, 3537-3545.

Cox R. J. (2007), Polyketides, proteins and genes in fungi: programmed nano-machines begin to reveal their secrets. Org. Biomol. Chem. 5, 2010-2026.

Doddapaneni H., Chakraborty R., and Yadav J. S. (2005), Genome-wide structural and evolutionary analysis of the P450 monooxygenase genes (P450ome) in the white rot fungus Phanerochaete chrysosporium: evidence for gene duplications and extensive gene clustering. BMC Genomics 6, 92.

Doekel S. and Marahiel M. A. (2001), Biosynthesis of natural products on modular peptide synthetases. Metab. Eng. 3, 64-77.

Hoegger P. J., Navarro-González M., Kilaru S., Hoffmann M., Westbrook E. D., and Kües U. (2004), The laccase gene family in Coprinopsis cinerea (Coprinus cinereus). Curr. Genet. 45, 9-18.

Jenni S., Leibundgut M., Maier T., and Ban N. (2006), Architecture of a fungal fatty acid synthase at $5 \AA$ resolution. Science 311, 1263-1267.

Jenni S., Leibundgut M., Boehringer D., Frick C., Mikolásek B., and Ban N. (2007), Structure of fungal fatty acid synthase and implications for iterative substrate shuttling. Science 316, 254-261. the ascomycetes: the $\beta$ subunit contains at its $\mathrm{C}$ terminus the ACP domain, which is the first domain at the $\mathrm{N}$-terminus of the $\alpha$ subunit in the ascomycetes (Fig. 1).

Due to the similarity in domain organization of the O. olearius FAS to the ascomycetous FASs it is likely that the $O$. olearius FAS forms a homohexamer equivalent to the $\alpha_{6} \beta_{6}$ dodecamer described for ascomycetes (Jenni et al., 2007).

\section{Acknowledgements}

This work was supported by the Deutsche Forschungsgemeinschaft (EI 766/1-1) and the state of Rhineland-Palatinate.

Kupfer D. M., Drabenstot S. D., Buchanan K. L., Lai H., Zhu H., Dyer D. W., Roe B. A., and Murphy J. W. (2004), Introns and splicing elements of five diverse fungi. Eukaryot. Cell 3, 1088-1100.

Laemmli U. K. (1970), Cleavage of structural proteins during the assembly of the head of bacteriophage T4. Nature (London) 227, 680-685.

Larrondo L. F., Gonzalez B., Cullen D., and Vicuña R. (2004), Characterization of a multicopper oxidase gene cluster in Phanerochaete chrysosporium and evidence of altered splicing of the mco transcripts. Microbiology 150, 2775-2783.

Lawen A. and Zocher R. (1990), Cyclosporin synthetase. The most complex peptide synthesizing multienzyme polypeptide so far described. J. Biol. Chem. 265, 11355-11360.

Leibundgut M., Jenni S., Frick C., and Ban N. (2007), Structural basis for substrate delivery by acyl carrier protein in the yeast fatty acid synthase. Science 316, 288-290.

Lynen F. (1980), On the structure of fatty acid synthetase of yeast. Eur. J. Biochem. 112, 431-442.

Maier T., Jenni S., and Ban N. (2006), Architecture of mammalian fatty acid synthase at $4.5 \AA$ resolution. Science 311, 1258-1262.

Martinez D., Larrondo L. F., Putnam N., Gelpke M. D., Huang K., Chapman J., Helfenbein K. G., Ramaiya P., Detter J. C., Larimer F., Coutinho P. M., Henrissat B., Berka R., Cullen D., and Rokhsar D. (2004), Genome sequence of the lignocellulose degrading fungus Phanerochaete chrysosporium. Nat. Biotechnol. 22, 695-700.

Piccioni R., Bellemare G., and Chua N.-H. (1982), Methods of polyacrylamide gel electrophoresis in the analysis and preparation of plant polypeptides. In: Methods in Chloroplast Molecular Biology (Edelman M., Hallik R. B., and Chua N.-H., eds.). Elsevier, Amsterdam, pp. 985-1014.

Rawlings B. J. (1998), Biosynthesis of fatty acids and related metabolites. Nat. Prod. Rep. 15, 275-308.

Schweizer E. and Hofmann J. (2004), Microbial type I fatty acid synthases (FAS): major players in a net- 
work of cellular FAS systems. Microbiol. Mol. Biol. Rev. 68, 501-517.

Welzel K., Eisfeld K., Antelo L., Anke T., and Anke H. (2005), Characterization of the ferrichrome A biosynthetic gene cluster in the homobasidiomycete Omphalotus olearius. FEMS Let. 249, 157-163.

Xu J., Saunders C. W., Hu P., Grant R. A., Boekhout T., Kuramae E. E., Kronstad J. W., Deangelis Y. M., Reeder N. L., Johnstone K. R., Leland M., Fieno A. M., Begley W. M., Sun Y., Lacey M. P., Chaudhary
T., Keough T., Chu L., Sears R., Yuan B., and Dawson T. L. Jr. (2007), Dandruff-associated Malassezia genomes reveal convergent and divergent virulence traits shared with plant and human fungal pathogens. Proc. Natl. Acad. Sci. USA 104, 18730-18735.

Zocher R., Keller U., and Kleinkauf H. (1982), Enniatin synthetase, a novel type of multifunctional enzyme catalyzing depsipeptide synthesis in Fusarium oxysporum. Biochemistry 21, 43-48. 